\title{
New Insights in the Treatment of Waste Water with Graphene: Dual-Site Adsorption by Sodium Dodecylbenzene Sulfonate
}

Israel Chavez-Sumarriva, ${ }^{1,2}$ Paul H. M. Van Steenberge, ${ }^{1}$ Dagmar R. D’hooge. ${ }^{1,3^{*}}$

${ }^{1}$ Laboratory for Chemical Technology (LCT), Ghent University, Technologiepark 914, B-9052 Gent, Belgium.

${ }^{2}$ Faculty of Chemistry and Chemical Engineering, National University of San Marcos, Lima 1, Lima, Peru

${ }^{3}$ Department of Textiles, Ghent University, Technologiepark 907, B-9052 Zwijnaarde (Gent), Belgium.

*Corresponding author: dagmar.dhooge@,ugent.be

\section{Table of Contents}

SI 1.Calibration details for UV-VIS measurements $\quad$ S2

SI 2.Derivation of isotherm for single-site adsorption $\quad$ S3

SI 3.Derivation of isotherm for dual site adsorption $\quad$ S4

$\begin{array}{ll}\text { SI 4.Reparameterization } & \text { S5 }\end{array}$

4.1 Derivation $\quad$ S5

4.2 Matrices $\quad$ S5

SI 5.Derivation of Pseudo-Second-Order Kinetics (dual-site adsorption) S6

SI 6.Identification of Limit contact time for validity of Pseudo-Second-Order Kinetics S8

SI 7.Incorrectness of the two-parameter estimation based on Equation (10) (or S40) S8

$\begin{array}{ll}\text { SI 8.References } & \text { S9 }\end{array}$ 


\section{SI 1. Calibration details for UV-VIS measurements}

Figure S1 shows UV-VIS spectra of SDBS in aqueous solution at different mass concentrations, all well below the critical micelle mass concentration that has a value between $4.210^{2}$ and $1.710^{3} \mathrm{mg} \mathrm{L}^{-1}$ ( $c a .293$ $\mathrm{K}){ }^{1-9}$ From these spectra, a linear calibration curve was constructed between the absorbance heights at $224 \mathrm{~nm}$ and the mass concentrations (see Figure S2). In practice, dilution needs to be performed to ensure measurement within the calibration range (dilution factor of 10 ).

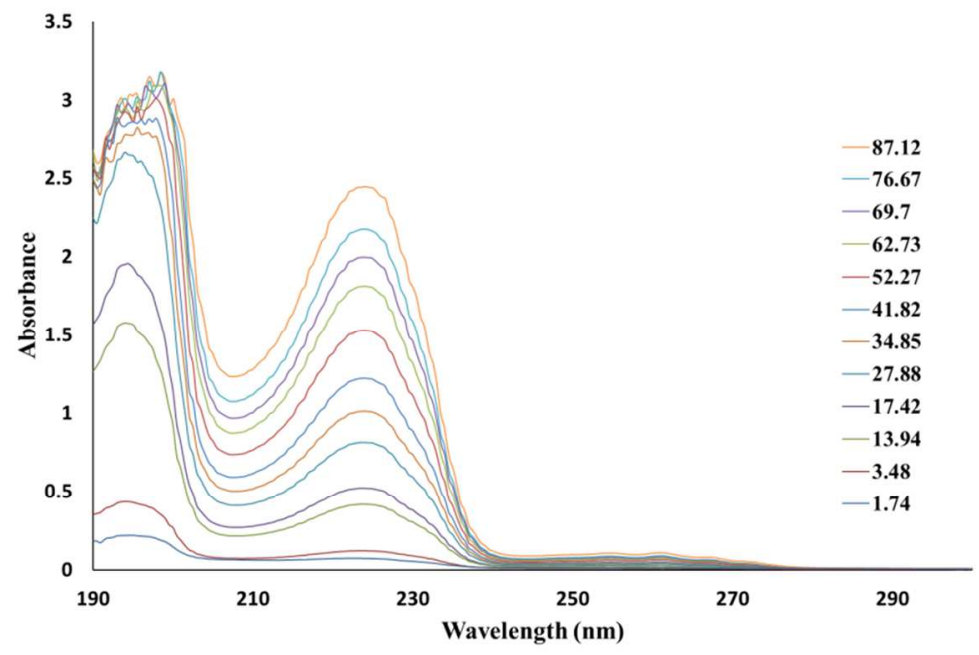

Figure S1. UV-VIS absorbance of SDBS at different mass concentrations $\left(\mathrm{mg} \mathrm{L}^{-1}\right)$; the height at 224 $\mathrm{nm}$ is used for the calibration curve (Figure S2).

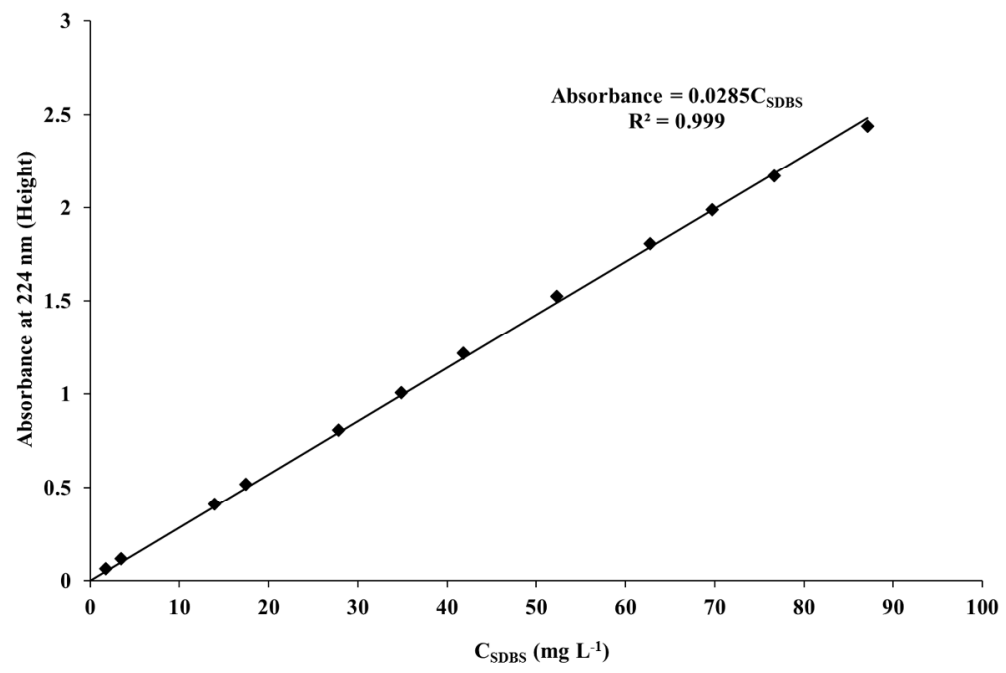

Figure S2. Calibration curve to obtain the SDBS mass concentration based on UV-VIS measurements (Figure 1). 


\section{SI 2. Derivation of isotherm for single-site adsorption}

Single-site adsorption can be expressed by following steps:

$$
\begin{gathered}
k_{1}^{+} \\
S+* \underset{\leftrightarrow}{\leftrightarrow} S * \\
k_{1}^{-}
\end{gathered}
$$

in which $S$ is a surfactant molecule, ${ }^{*}$ an active site on the graphene surface, $\mathrm{S}^{*}$ the corresponding occupied site, $k_{l}{ }^{+}$the adsorption rate coefficient, and $k_{l}{ }^{-}$the desorption rate coefficient. The adsorption and desorption rate are given by:

$r_{a}=k_{1}^{+} C_{S, t} \theta_{*}$

$r_{d}=k_{1}^{-} \theta_{t}$

in which $C_{S, t}$ is the SDBS mass concentration in solution and $\theta_{t}$ is defined as the fraction of the active sites occupied by the surfactant molecules. This fraction also results from:

$\theta_{t}=\frac{q_{t}}{q_{\infty}}$

with $q_{t}$ and $\mathrm{q}_{\infty}$ respectively the adsorption capacity at a given time and the corresponding theoretical maximal value.

In addition, following balance holds for the sites:

$\theta_{t}+\theta_{*}=1$

Inserting equation (S5) in Equation (S2), the continuity equation for the occupied active sites can be expressed as:

$\frac{d \theta_{t}}{d t}=r_{a}-r_{d}=k_{1}^{+} C_{S, t}\left(1-\theta_{t}\right)-k_{1}^{-} \theta_{t}$

At equilibrium, the derivative becomes zero and $\theta_{\mathrm{t}}$ and $\mathrm{C}_{\mathrm{S}, \mathrm{t}}$ becomes equal to their equilibrium values, allowing following manipulations:

$0=k_{1}^{+} C_{S, e q}\left(1-\theta_{e q}\right)-k_{1}^{-} \theta_{e q}$ 
$\theta_{e q}\left(k_{1}^{-}+k_{1}^{+} C_{S, e q}\right)=k_{1}^{+} C_{e q}$

$\theta_{e q}=\frac{k_{1}^{+} C_{S, e q}}{k_{1}^{-}+k_{1}^{+} C_{S, e q}}$

Taking into account the definition of the single-site adsorption equilibrium coefficient:

$K_{1}=\frac{k_{1}^{+}}{k_{1}^{-}}$

and considering Equation (S4) the well-known Langmuir isotherm follows:

$q_{e q}=\frac{q_{\infty} K_{1} C_{S, e q}}{1+K_{1} C_{S, e q}}$

\section{SI 3. Derivation of isotherm for dual-site adsorption}

In the present work, for the first time, the isotherm for dual-site adsorption is derived. Dual-site adsorption can be expressed by following steps:

$S+2 * \stackrel{k_{2}^{+}}{\leftrightarrow} S * *$

in which $S$ is a surfactant molecule, $*$ is an active site on the graphene surface, $\mathrm{S}^{* *}$ an adsorbed surfactant molecule occupying two adjacent sites, $k_{2}{ }^{+}$the adsorption rate coefficient, and $k_{2}{ }^{-}$the desorption rate coefficient. The adsorption and desorption rate are given by:

$r_{a}=k_{2}^{+} C_{S, t} \theta_{*}^{2}$

$r_{d}=k_{2}^{-} \theta_{t}$

Inserting Equation (S5) in Equation (S13), the continuity equation for the occupied active sites becomes:

$\frac{d \theta_{t}}{d t}=r_{a}-r_{d}=k_{2}^{+} C_{S, t}\left(1-\theta_{t}\right)^{2}-k_{2}^{-} \theta_{t}$

At equilibrium the derivative becomes zero and $\theta_{\mathrm{t}}$ and $C_{S, e q}$ become equal to their equilibrium values, allowing following manipulations: 
$0=k_{2}^{+} C_{S, e q}\left(1-\theta_{e q}\right)^{2}-k_{2}^{-} \theta_{e q}$

$k_{2}^{+} C_{S, e q} \theta_{e q}^{2}-\left(2 k_{2}^{+} C_{S, e q}+k_{2}^{-}\right) \theta_{e q}+k_{2}^{+} C_{S, e q}=0$

$\theta_{e q}^{2}-\left(2+\frac{k_{2}^{-}}{k_{2}^{+} C_{S, e q}}\right) \theta_{e q}+1=0$

Taking into account the definition of the dual-site adsorption equilibrium coefficient (Equation S19), $\theta_{e q}$ can be determined, by calculating the analytical solution for a quadratic equation (discriminant $D$ ):

$K_{2}=\frac{k_{2}^{+}}{k_{2}^{-}}$

$\theta_{e q}^{2}-\left(2+\frac{1}{K_{2} C_{S, e q}}\right) \theta_{e q}+1=0$

$D=\left(2+\frac{1}{K_{2} C_{S, e q}}\right)^{2}-4$

$\theta_{e q}=\frac{\left(2+\frac{1}{K_{2} C_{S, e q}}\right) \pm \sqrt{\left(2+\frac{1}{K_{2} C_{S, e q}}\right)^{2}-4}}{2}$

Since $\theta_{e q}$ can be maximally 1 , the solution resulting after selecting the minus sign is the only physical one. After inserting Equation (S4), the equation in the main text is obtained:

$q_{e q}=q_{\infty}\left(1+\frac{1}{2 K_{2} C_{S, e q}}\right)-q_{\infty} \sqrt{\left(1+\frac{1}{2 K_{2} C_{S, e q}}\right)^{2}-1}$

\section{SI 4. Reparameterization}

As explained in the main text, reparameterization is performed to reduce the correlation between the parameter estimates for the isotherm. Such reparameterization is performed around the average temperature $T_{a v g}$ (see S4.1). The relevance of this reparameterization is showcased in S4.2.

\section{SI 4.1 Derivation}

$K_{i, a d s}^{\circ}(T)=\exp \left(\frac{\Delta_{i} S^{\circ}}{R}-\frac{\Delta H^{\circ}}{R T}\right)$ 


$$
\begin{aligned}
& K_{i, a d s}^{\circ}\left(T_{a v g}\right)=\exp \left(\frac{\Delta_{i} S^{\circ}}{R}-\frac{\Delta H^{\circ}}{R T_{a v g}}\right) \\
& K_{i, a d s}^{\circ}(T)=K_{i, a d s}^{\circ}\left(T_{\text {avg }}\right) \exp \left(\frac{-\Delta_{i} H^{\circ}}{R}\left(\frac{1}{T}-\frac{1}{T_{\text {avg }}}\right)\right)
\end{aligned}
$$

\section{SI 4.2 Matrices}

Table S1: Correlation matrix for model 2 (without reparameterization);

$\underset{\Delta_{2} S^{\circ}}{\Delta_{\infty} H^{\circ}}\left[\begin{array}{ccc}\Delta_{2} H^{\circ} & \Delta_{2} S^{\circ} & \mathrm{q}_{\infty} \\ 1.00 & 0.99 & 0.30 \\ 0.99 & 1.00 & 0.20 \\ 0.30 & 0.20 & 1.00\end{array}\right]$

Upon comparison with the matrix in the main text (with reparameterization) it is clear that by reparameterization the absolute values of the non-diagonal elements can be reduced below 0.95 , which is a threshold value as explained in the main text. The same conclusion holds for model 1 (Table S2).

Table S2: Correlation matrix for model 1 (with reparameterization (left) and without reparameterization (right))

With Reparameterization

\begin{tabular}{|c|c|c|c|c|c|c|c|}
\hline & $\Delta_{1} H^{\circ}$ & $K_{1, a d s}^{0}\left(T_{r e f}\right)$ & $q_{\infty}$ & & $\Delta_{1} H^{\circ}$ & $\Delta_{1} S^{\circ}$ & $\mathrm{q}_{\infty}$ \\
\hline$\Delta_{1} H^{\circ}$ & 1.00 & -0.29 & 0.22 & $\Delta_{1} H^{\circ}$ & 1.00 & 0.99 & 0.15 \\
\hline$K_{1, a d s}^{0}\left(T_{r e f}\right)$ & -0.29 & 1.00 & -0.83 & $\Delta_{1} S^{\circ}$ & 0.99 & 1.00 & 0.08 \\
\hline $\mathrm{q}_{\infty}$ & 0.22 & -0.83 & 1.00 & $\mathrm{q}_{\infty}$ & 0.15 & 0.08 & 1.00 \\
\hline
\end{tabular}

Without Reparameterization

\section{SI 5. Derivation of Pseudo-Second-Order Kinetics (dual-site adsorption)}

Ignoring the desorption contribution in Equation S15 it follows that:

$\frac{d \theta_{t}}{d t}=r_{a}=k_{2}^{+} C_{S, t}\left(1-\theta_{t}\right)^{2}$

By following manipulations $\left(\theta_{e q}-\theta_{t}\right)^{2}$ can be isolated: 


$$
\begin{aligned}
& \frac{d \theta_{t}}{d t}=k_{2}^{+} C_{S, t}\left(\left(1-\theta_{e q}\right)+\left(\theta_{e q}-\theta_{t}\right)\right)^{2} \\
& \frac{d \theta_{t}}{d t}=k_{2}^{+} C_{S, t}\left(\theta_{e q}-\theta_{t}\right)^{2}\left(1+\frac{\left(1-\theta_{e q}\right)}{\left(\theta_{e q}-\theta_{t}\right)}\right)^{2}
\end{aligned}
$$

Upon ignoring the second term in the last factor, i.e.

$$
\frac{\left(1-\theta_{e q}\right)}{\left(\theta_{e q}-\theta_{t}\right)}
$$

which is most reasonable at low times it follows that:

$\frac{d \theta_{t}}{d t}=k_{2}^{+} C_{S, t}\left(\theta_{e q}-\theta_{t}\right)^{2}$

At low times, it can further be claimed that $\mathrm{C}_{\mathrm{S}, \mathrm{t}} \approx \mathrm{C}_{\mathrm{S}, 0}$ so that

$\frac{d \theta_{t}}{d t}=k_{2}^{+} C_{S, 0}\left(\theta_{e q}-\theta_{t}\right)^{2}$

The following pseudo-second order coefficient can thus be defined:

$$
k_{2, \text { app }}{ }^{\prime}=k_{2}^{+} C_{S, 0} \text { in } \mathrm{h}^{-1}
$$

By taking into account the definition of $\theta_{t}$ (Equation S4) further rewriting allows to derive the typically postulated second-order kinetics equation in literature ${ }^{10,11}$ (Equation S37):

$$
\begin{aligned}
& \frac{1}{q_{\infty}} \frac{d q_{t}}{d t}=k_{2}^{+} C_{S, 0}\left(\frac{q_{e q}}{q_{\infty}}-\frac{q_{t}}{q_{\infty}}\right)^{2} \\
& \frac{d q_{t}}{d t}=\frac{k_{2}^{+} C_{S, 0}}{q_{\infty}}\left(q_{e q}-q_{t}\right)^{2} \\
& k_{2, a p p}=\frac{k_{2}^{+} c_{S, 0}}{q_{\infty}} \text { in } \mathrm{g}_{\mathrm{rGO}} \mathrm{mg}_{\mathrm{SDBS}}{ }^{-1} \mathrm{~h}^{-1} \\
& \frac{d q_{t}}{d t}=k_{2, a p p}\left(q_{e q}-q_{t}\right)^{2}
\end{aligned}
$$

Note that in the last step a new pseudo-second order rate coefficient $\left(k_{2, a p p}\right)$ has been introduced with updated dimensions compared to Equation S33.

Furthermore, rearranging Equation (S37) as: 
$-\frac{1}{\left(q_{e q}-q_{t}\right)^{2}} d\left(q_{e q}-q_{t}\right)=k_{2, a p p} d t$

and integration with the boundary conditions $q_{\mathrm{t}}=0$ at $t=0$ and $q_{t}=q_{t}$ at $t$ :

$\int_{0}^{q_{t}} \frac{-1}{\left(q_{e q}-q_{t}\right)^{2}} d\left(q_{e q}-q_{t}\right)=\int_{0}^{t} k_{2, a p p} d t$

allows to obtain after some manipulations:

$\frac{t}{q_{t}}=\frac{1}{k_{2, a p p} q_{e q}^{2}}+\frac{t}{q_{e q}}$

which is the starting equation for further derivations, as done in the main text. In particular, the estimation of $k_{2, a p p}$ allows to obtain $k_{2}^{+}$via Equation (S36).

Note that this strictly only an assessment of $k_{2}{ }^{+}$is obtained, since the factor as given by Equation (S30) has been ignored. A more accurate value can be obtained by correcting the previous $k_{2}^{+}$value by calculating the average value of the ignored factor (Equation S41) for the selected time period for the application of the pseudo-second-order conditions. In the present work, this period is from 0 to 10 hours, leading to an average correction factor of 2.4 for $k_{2}{ }^{+}$, using the data in Table S3.

$\left(1+\frac{\left(1-\theta_{e q}\right)}{\left(\theta_{e q}-\theta_{t}\right)}\right)^{2}$

Table S3: Calculation of correction factor for a more accurate $k_{2}^{+}$; note that averaging is acceptable as the time dependency for this factor is acceptable; average value of 2.4

\begin{tabular}{cc}
\hline Time (h) & Value for Equation (S41) \\
1 & 1.95 \\
3 & 2.08 \\
6 & 2.57 \\
9 & 3.15 \\
\hline
\end{tabular}




\section{SI 6. Identification of limiting contact time for validity of pseudo-second-order kinetics}

From Figure S3 it can be observed that the pseudo-second-order conditions are only reasonably valid until 10 hours, explaining why in the main text only the first four points have been selected for the parameter estimation.

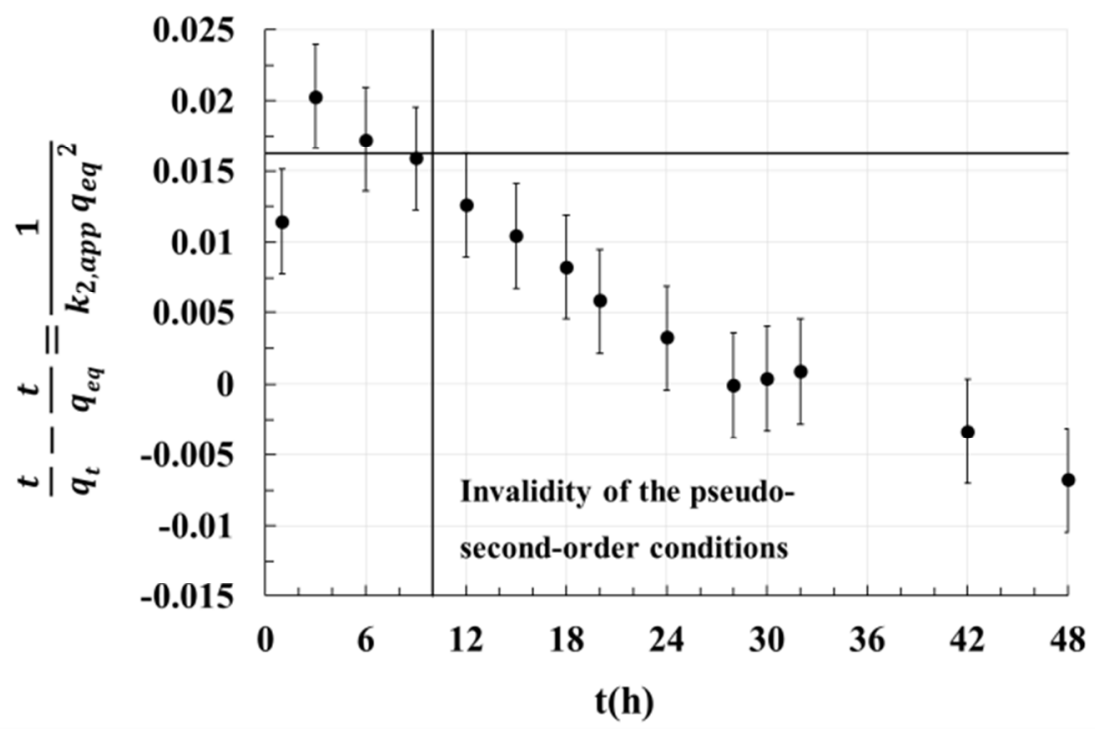

Figure S3. Invalidity of the pseudo-second-order conditions for the complete time range to obtain $k_{2}^{+}$via Equation (10) in the main text up to 48 hours.

\section{SI 7. Incorrectness of the two-parameter estimation based on Equation (10) (or S40)}

Figure S4(a) and Figure S4(b) show that it can be misleading to directly apply the model for pseudosecond-order kinetics for the complete time range ( 0 to 48 hours). A good description can namely be obtained despite that the pseudo-second-order kinetics are only acceptable until 10 hours, as explained in the previous section. The reason is that with a two-parameter estimation (Equation (10) in the main text or Equation S40) a compensation can be made, leading only to an approximate value for $q_{e q}\left(526.32 \mathrm{mg}_{\mathrm{SDBS}}\right.$ $\mathrm{g}_{\mathrm{rGO}}{ }^{-1}$; Figure $\mathrm{S} 4(\mathrm{~b})$ as confirmed by the comparison with the actual $q_{e q}$ value as obtained with the full thermodynamic analysis (Figure 1: $412.1 \mathrm{mg}_{\mathrm{SDBS}} \mathrm{g}_{\mathrm{rGO}}{ }^{-1}$ ). Due to this mismatch, also for $k_{2}^{+}$an incorrect value is obtained (see caption Figure S4). 


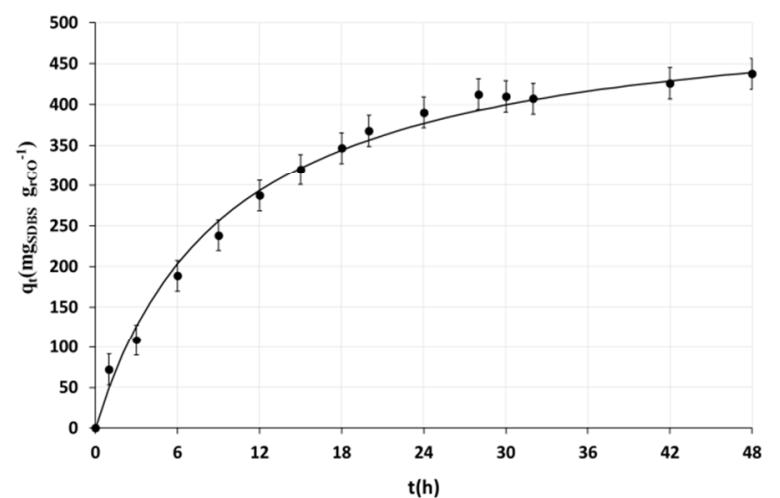

(a)

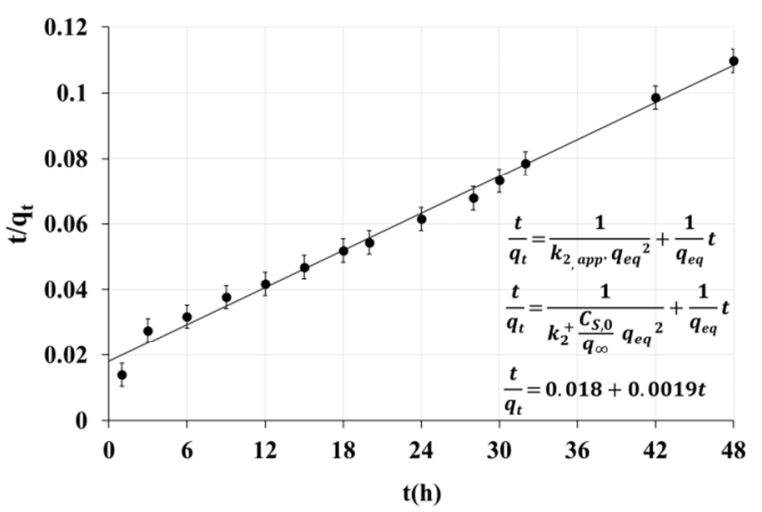

(b)

Figure S4. (a) Effect of the contact time $t$ on the adsorption of SDBS on reduced graphene oxide (rGO); initial conditions: entry 1 in Table 1 (no NaCl): points: experimental data; full line: description with invalid pseudo-second-order kinetic model until 48 hours; (b) Regression analysis to obtain $k_{2, a p p}=0.0002 \mathrm{~g}_{\mathrm{rGO}} \mathrm{mg}_{\mathrm{SDBS}}{ }^{-1} \mathrm{~h}^{-1}$ and $q_{e q}=526.32 \mathrm{mg}_{\mathrm{SDBS}} \mathrm{g}_{\mathrm{rGO}}{ }^{-1}$ leading to $k_{2}^{+}=1.210^{-4} \mathrm{~L}$ $\mathrm{mg}_{\mathrm{SDBS}}{ }^{-1} \mathrm{~h}^{-1}$ with $C_{S, 0}=700 \mathrm{mg}_{\mathrm{SDBS}} \mathrm{L}^{-1}$; multiple correlation coefficient $R^{2}=0.990$; due to the consideration of the complete time range incorrect parameter values are obtained; only the low times can be used (see Figure S3).

\section{SI 8. References}

1. Chauhan, S.; Sharma, K. Effect of temperature and additives on the critical micelle concentration and thermodynamics of micelle formation of sodium dodecyl benzene sulfonate and dodecyltrimethylammonium bromide in aqueous solution: A conductometric study. J. Chem. Thermodyn. 2014, 71, 205-211.

2. Shimoda, S.; Smela, E. The effect of $\mathrm{pH}$ on polymerization and volume change in $\operatorname{PPy}(\mathrm{DBS})$. Electrochim. Acta 1998, 44, 219-238.

3. Naoi, K.; Oura, Y.; Maeda, M.; Nakamura, S. Electrochemistry of Surfactant-Doped Polypyrrole Film(I): Formation of Columnar Structure by Electropolymerization. J. Electrochem. Soc. 1995, 142, 417422.

4. Karami, H.; Mousavi, M. F. Dodecyl benzene sulfonate anion-selective electrode based on polyaniline-coated electrode. Talanta 2004, 63, 743-749.

5. Segota, S.; Heimer, S.; Tezak, D. New catanionic mixtures of dodecyldimethylammonium bromide/sodium dodecylbenzenesulphonate/water. Colloids Surf., A 2006, 274, 91-99.

6. Mahajan, R. K.; Shaheen, A. Effect of various additives on the performance of a newly developed PVC based potentiometric sensor for anionic surfactants. J. Colloid Interface Sci. 2008, 326, 191-195.

7. Tadros, T. F. Applied surfactants: Principles and applications. Wiley-VCH: Weinheim, 2005.

8. Paisal, R.; Martínez, R.; Padilla, J.; Romero, A. J. F. Electrosynthesis and properties of the polypyrrole/dodecylbenzene sulfonate polymer. Influence of structural micellar changes of sodium dodecylbenzene sulfonate at high concentrations. Electrochim. Acta 2011, 56, 6345-6351.

9. Valente, A. J. M.; López Cascales, J. J.; Fernández Romero, A. J. Thermodynamic analysis of unimer-micelle and sphere-to-rod micellar transitions of aqueous solutions of sodium dodecylbenzenesulfonate. J. Chem. Thermodyn. 2014, 77, 54-62. 
10. Ho, Y. S.; McKay, G. Pseudo-second order model for sorption processes. Process Biochem. 1999, 34, 451-465.

11. Ho, Y. S.; McKay, G. The kinetics of sorption of divalent metal ions onto sphagnum moss peat. Water Res. 2000, 34, 735-742. 